\title{
FUTURE OF DWELLING: THE ADVANTAGES OF PREFABRICATION IN ALLEVIATING THE RESIDENTIAL CRISIS
}

\author{
CAMILO CERRO \\ American University of Sharjah, UAE
}

\begin{abstract}
The United States is facing an affordable housing crisis which is affecting people across the whole income spectrum. In 2018, the National Income Housing Coalition found that there is no state where a renter, working full-time at minimum wage can afford a two-bedroom apartment. Nationally, there is a shortage of more than four million affordable homes which in turn increases the price of all existing dwellings. This results in nearly $60 \%$ of renters nationwide unable to buy a home, with $70 \%$ of lowincome families severely cost-burdened, paying more than half their income on rent. Even as the economy continues to grow and the housing market rebounds from the 2008 recession, the population faces widening inequality. For many, an inability to comfortably pay for housing, stagnation of wages and increasing housing cost is making housing insecurity one of the hidden truths of the present real estate market. COVID-19 has made the situation more complicated by raising the cost of labor and materials, due to a scarcity of both, which makes affordable housing expensive to build and the attempt to follow a sustainable construction system of circular economy very complicated. Since accessible housing is the key to reducing intergenerational poverty and increasing economic mobility, a solution needs to be found. This article will present an overview of the prefabrication industry resulting in a design to be used as a case study to test the feasibility of this construction manufacturing process, to test why the future of dwelling resides in prefabrication.
\end{abstract}

Keywords: affordable housing, prefabrication, interdependence, COVID-19, housing insecurity, inequality, economic mobility.

\section{INTRODUCTION}

Long waiting lists, high rents, thousands homeless, millions living in insecure or unsuitable dwellings and a generation of young people priced out of the housing market are the main characteristics of the US's broken housing system. As supply fails to keep up with demand, home prices nationwide are rising at twice the rate of incomes and three times the rate of inflation [1]. The affordable housing crisis continues to be a major problem in the United States, and it is getting worst every year. For a sector that generates more than $\$ 640$ billion in GDP, employing around 7 million people, and building $\$ 1.3$ trillion worth of construction every year, the cost of doing nothing to fix the problem is not an option. Several interdependent elements are needed to deal with this crisis. The first is removing regulatory barriers at the local, state, and federal level to allow more homes and apartments to be built. This needs innovation on the construction industry side to build faster, increase productivity, and lower costs. Followed by creative finance allowing more people to qualify for a mortgage to buy a home, and to provide more affordable housing for renters. And finally, getting more access to land to provide greater housing opportunities. This article will discuss issues directly related to the construction process and the advantages of using prefabricated construction systems to help alleviate the residential crisis. Prefabrication or industrialized building systems (IBS) is a mass production industrialized construction process that uses emerging technologies and a manufacturing factory model to produce modular architecture in a controlled environment (off-site) through an efficient logistical construction schedule, planning and management. 


\section{THE PROBLEM}

The US economy has recovered and expanded since the great recession of 2008, except in the housing market. For the last 12 years, housing shortage and costs have been the most significant factor in preventing the younger generations from attaining their own households (Fig. 1). But why do we have a housing shortage? A few of the most cited reasons feeding this problem are, the lack of available skilled construction labor, land use regulations, zoning restrictions, lack of land developers and a lack of land to develop. After nearly a decade of low levels of residential construction, the US housing market is 3.8 million single-family homes short of what is needed to meet the country's present demand [2]. And according to Freddie Mac, these units are needed not only to meet the demand from the growing number of households but also to maintain a target vacancy rate of $13 \%$. The combination of a low supply of entry-level units and high demand for the same, is causing entry-level prices to rise, triggering affordability issues for buyers. If supply continues to fall short of demand, home prices and rents in the United States are likely to outpace family income.

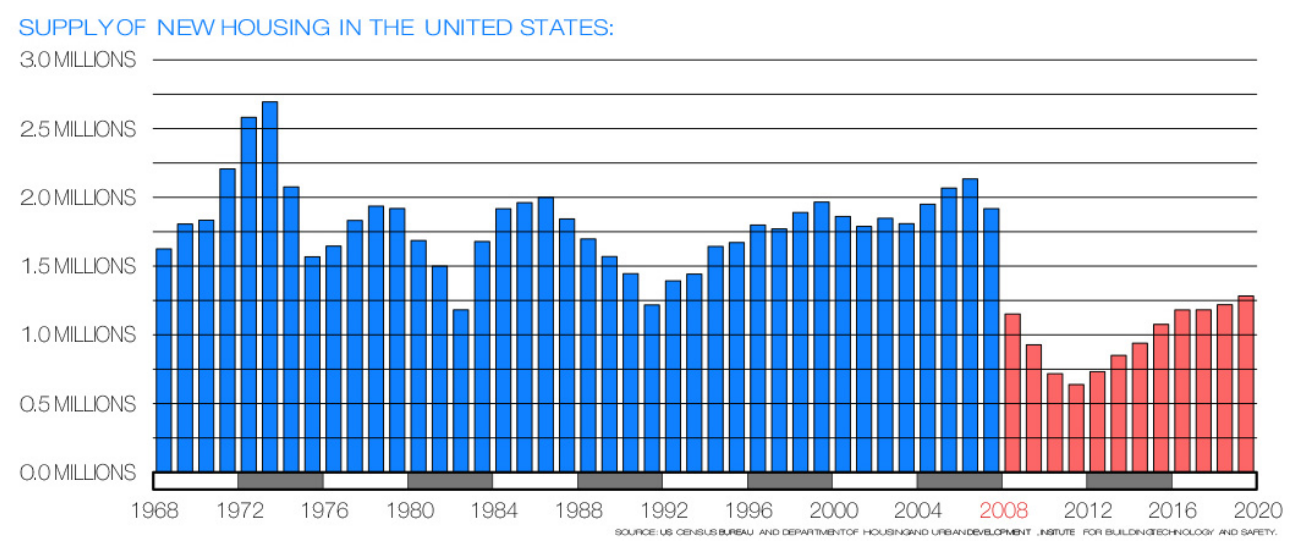

Figure 1: Supply of new housing in the United States after 2008 [3].

\section{PREFAB MODULARITY: A BRIEF HISTORY}

Known as Mill-cut Houses, Pre-cut Houses, Mail Order Homes, Catalogue Homes or Kit Houses, the predecessor to the modular homes became a part of North American life in the first half of the 20th century. Sold through catalogue, a home buyer would send a check to one of the multiple companies selling mail order homes, and a house kit including blueprints and construction materials would be shipped back via railroad or boat to a depot close to the customer's hometown. From there, the new owner was responsible for transporting the kit to the construction site. The first kit homes were sold through catalogue by the Aladdin Company from Bay City, Michigan in 1906 followed by Sears \& Roebuck and Co. in 1908. The company had a long life, manufacturing modular houses that started in 1906 and ended in 1981. In this period of time, they sold more than 75,000 homes domestically and internationally to both families and corporations. Advertised as Readicut and Built in a day, Aladdin and other kit home manufacturers like Montgomery Ward, Lewis and Sears \& Roebuck and Co. revolutionized the access to affordable housing for the middle class. Their best seller from 1890 to the $1930 \mathrm{~s}$ was the Foursquare kit home named the Rochester [4], which sold for $\$ 1,387.00$ dollars (Fig. 2). The average Home-kit had 25 
tons of materials, with over 30,000 parts. The key to the kit revolved around the pre-cut lumber which arrived cut to the right length, width, and thickness.
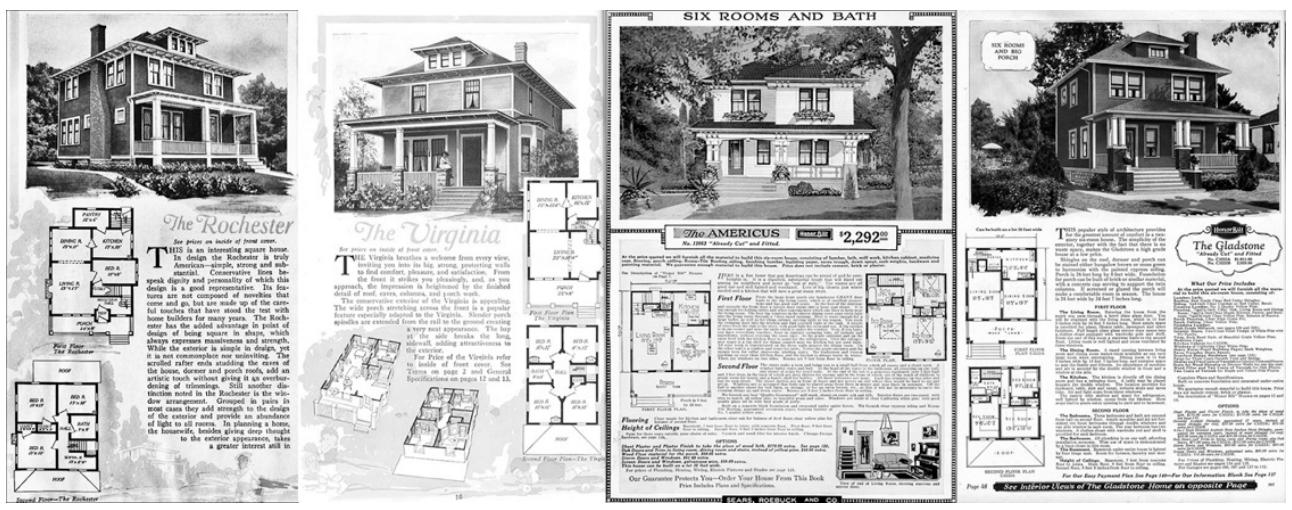

Figure 2: Four square kit-homes samples including the Rochester by Aladdin Company.

The use of balloon framing and pre-cut and fitted materials, cut construction time by up to $40 \%$. The ability to mass-produce the materials used lessened manufacturing costs, which lowered purchase costs for customers. Each piece had a stamp with a unique code designed for easy assembly. The kit also included an instruction manual (averaging around 70 pages) designed to guide the new owner in the construction process which was advertised to take even the most rudimentary builder around 90 days to assemble (a precursor to IKEA). Electricity, plumbing, and heating were not included in the basic kit but could be added as at an extra cost. Also, for an extra fee, the house could be customized. While some built their own homes, most buyers hired local construction companies to assemble the kits, paying only for labor cost. The kit home served as a good predecessor for residential modularity. Richard Sears in 1913, following Henry Ford's use of the assembly line, had the idea of building family homes in a factory using a similar system. This idea would have as an advantage keeping all the skilled labor in one place resulting in lower production costs. Ready to assemble homes remained popular until the stock market crash of 1929. After that, the middle class could not afford to buy homes anymore and some of the companies making kit homes went out of business. It wasn't until the post war era (1950s) that the modular home became popular again. The returning troops wanting to start families needed homes. The modular home, now easier and cheaper to transport, thanks to the new highway system surged in popularity again. In 1943, Skidmore, Owings \& Merrill (SOM) built secretly 3000 prefabricated houses to house members of the Manhattan Project in a location now known as Oak Ridge, Tennessee. In 1958 the first double wide home was built. A double-wide is a prefabricated modular home measuring around 90 feet $(27 \mathrm{~m})$ in length and 20 feet $(6.1 \mathrm{~m})$ in width, which is towed as two separate units to the site where they are joined together. Many home building companies saw the benefits of building sections of a house in a factory setting. The popularity of this type of home led the federal government to regulate the construction process. And in 1976 the US Department of Housing and Urban Development created the building code (HUD code) setting standards for both modular and traditional homes. Modular home construction had to adapt to new codes pertaining to fire safety, structural design, heating, plumbing and electrical systems. In the second part of the 20th century some failed attempts at designing 
modular homes were made by very famous designers: Le Corbusier proposed his Dom-Ino post war typology, Jean Prouve his Maison Demontable, Frank Lloyd Wright his American System-Built Home, Buckmister Fuller his Dymaxion House, Richard Rogers his Zip-up house and Philippe Starck his Prefabricated Accessible Technological Home (PATH). Today, the modern modular home is built in an eco-friendly way, using Structurally Insulated Panels (SIP) panels, at a factory. The pieces are transported by truck to the site and assembled. And they are no longer purchased through catalog, or maybe they are, if we consider the internet to be one.

\section{MODULAR ARCHITECTURE: THE FUTURE OF AFFORDABLE HOUSING}

Even though historically, some of the first ideas about prefabrication started in the United States, when we look at modern prefab modular architecture, we must look at places like Sweden, Japan, and the Netherlands. And that is because while in the US, Australia, or the UK no more than $5 \%$ of permanent housing has prefabricated elements, $84 \%$ of all detached houses use them in Sweden, $15 \%$ in Japan and 20\% in the Netherlands [5]. The United States has fallen behind because of a lack of the demand drivers of these leading countries, including in some cases: extreme weather, earthquakes, or environmental activism. In January 2003, Dwell Magazine issued a design challenge to 16 architecture firms to design a prefab home for $\$ 200,000.00$ to start a conversation about prefab modularity and to change this trend. The competition was won by Resolution:4 Architecture, who developed a building system based on prefabricated modules produced in a factory environment, transported by truck to the site, and then craned onto a concrete foundation designed to house all the dwelling's mechanical systems [6]. The house was composed of two intersecting bars overlapping each other. The top module housed the private areas of the house while the bottom one did the same for the communal spaces. And while it is true that much of the public appeal of prefab has been tied to cost savings, for the owners of the winning house, those savings were proven to be not as significant as they might have hoped for. But the competition did show the public in general not to underestimate the efficiency, precision and the time savings in the prefab construction process, something not often seen in today's building practices. Because architecture has always been tied to the construction industry, prefabrication has the potential to help fix an industry that suffers from inefficiencies that are harmful to the client's time and money [7], and the environment as a whole [8]. Material waste, the high cost of labor, the length of construction times and troublesome levels of maintenance are a few of the many consequences of today's outdated building construction practices. Contributing to the inefficiencies there is a lack of standardized workflow between the different construction trades. And on top of that, there is also a skilled labor shortage, due to a combination of; Millennials not going into the construction industry, nationalist immigration policies, the Boomer generation starting to retire and the COVID-19 pandemic. The entire building community needs to reform itself, but this is going to be very hard due to all the special interest groups at play.

As this industry starts to become more dependent on technology, we start to see less waste, better scheduling, and a faster construction process. The construction process needs to resemble more that of car manufacturing, because factory construction is a big part of cutting construction costs. The benefits extend also to the workers [9], who get better paid, get training, the controlled setup makes a hard job easier, there is no more commuting to different job sites, and they have a job every day, regardless of what the weather is like. And it also benefits the neighbors by creating less construction disruption in the neighborhoods thanks to the short time of onsite work that the prefab system requires. 
While traditional construction cost has been rising between $5-10 \%$ annually for the past three years [10], modern prefab modular construction can reduce the cost of construction by $20-40 \%$ and the construction time by $30-40 \%$. And although modular construction represents only $3 \%$ of homes in the market [11], this number is growing, presenting a concrete and promising alternative to help alleviate the affordable housing crisis. A proof of this is that the tech industry is noticing. In 2017, Google spent $\$ 30$ million to build 300 modular housing units for its employees in San Francisco [12]. The project was built by Factory OS. Microsoft is investing half a billion dollars in a similar project in Seattle [13]. And if the tech industry has noticed, the government will follow. As seen in Brooklyn, where the New York City Affordable Housing Agency is explicitly requiring modular housing construction as part of their Housing New York 2.0 Plan [14]. Other cities are seeing the benefits, having plans to use modular construction in the creation of homeless shelters. So, if the projects keep flowing and the factories are kept busy, modular construction seems to be creating a space for itself in the building industry.

\section{UNDERSTANDING THE MODULAR PREFAB CONSTRUCTION PROCESS}

In the United States, companies like: RAD Urban, Factory OS, Plant Prefab, Roombus, Dvele, Entekra, Katerra, Fullstack Modular, Blokable, Blu Homes, Connect Homes and Method Homes, are layering smart and prefab technologies, promising a more holistic approach to homebuilding that considers the entire life cycle of the home. These companies are inclined to be more progressive and advanced in the way they are building homes, investing in technologies that are yielding zero utility bills, require less maintenance, and are more durable and resilient. Each company seems to have their own take on modular construction and their own strategy for reshaping the building industry. While each company has their own specialties, the construction building process (Fig. 3) follows more or less the same parameters for all of them. Projects are digitally designed and streamlined with exacting precision before assembly begins. Once in the factory, the first stage on building a prefabricated house starts with welding a steel frame the size of the module (14'

$\times 76^{\prime}$ max. due to shipping restrictions). This, followed by joists, decking and the floor being installed onto the frame. Which in the factory is set to about 6 feet $(1.8 \mathrm{~m})$ above grade allowing for workers to work simultaneously above and below it. The second stage attaches the walls, which have been built separately and are brought assembled to be positioned vertically, over the flooring and frame. At this point the designed interior wall finishes are added, followed by windows, insulation, electrical wiring, plumbing, and any custom components. While this is taking place, the roof is being put together at another station. As the module moves down the assembly line, an overhead crane hoists the roof onto the walls as part of the third stage. And finally, on the last stage, the interior is finished, built-ins and fixtures are added. While inside the roof, ductwork is run, as well as additional electrical wiring and other components. Exterior finishes and weather proofing are attached while doors, interior trim and cabinets are completed. In a typical modular construction project, up to $90 \%$ of the construction is completed in the factory. This system cuts down time. Once fabrication starts, all the time-space management has already been done to understand the labor required at each stage, defining the number of staff needed for each task. It takes about 14 days for a module to be constructed from beginning to end in the factory, after which is taken to the site where it is assembled to other modules like Legos, capable of rising to 5 story tall if designed to do so. The biggest bottleneck is the process of getting planning approval. Whether building off-site or traditionally, you cannot start building unless you have planning permission. In the end, a fully integrated prefabricated project offers a lot of benefits and can be cost-effective by allowing for 
minimum material wastage, decreased amount of equipment used on-site, fewer resource requirements, increased control due to factory production, and decreased operational and labor cost due to short project timeline. All of which benefits the client and the environment.

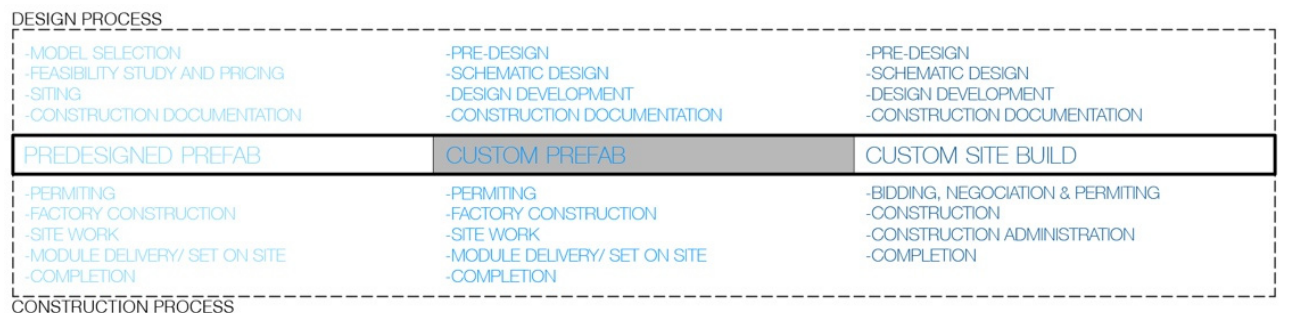

Figure 3: Pre-designed prefab vs. custom prefab vs. custom build construction process comparison.

\section{WHAT IT MEANS FOR SUSTAINABILITY}

Around $40 \%$ of landfill waste in the United States, comes from the construction industry. The US Environmental Protection Agency estimates that 600 million tons of construction and demolition waste were added to landfills in 2018 [12]. And while moving construction off-site into factories holds a lot of promise for efficiency and innovation, it can also have a positive impact on construction waste management, reducing environmental impact and conserving resources. The possibility of applying circular economy principles to prefabrication [15] to achieve these goals is not only possible but is already in use as part of prefabrication building systems models [16]. The construction process when held in a controlled environment gives the builder more oversight over inventories, allowing for any leftover material to be recycled and reused in future projects, reducing the construction waste that ends up in the landfill. The controlled environment created in the factory also uses less energy than a traditional construction project and allows for large portion of works to be completed simultaneously, reducing the construction time. Soft costs like: Real estate fees, inspection fees, project management, and taxes, are minimized thanks to the fast pace of the construction process. Buildings are designed and built to the same or to have higher sustainability standards as those of traditional construction. Europe is a good example in that they require that all new homes are Net Zero and fabricators are building to Passive House standards which is the most rigorous building performance system in the world at this moment. Modular prefabricated houses following Passive House requirements have reduced energy consumption by up to $90 \%$ when compared with traditional construction [17]. Another sustainable advantage is that since most of the construction process takes place off-site there is less impact to the building site and surrounding community, since site construction time is shorten, covering only foundation work, landscaping, and the setup of the modules. Through innovation and control, factory prefabrication is playing a major role in making the building sector more sustainable in ways not seen in traditional construction. 


\section{METHODOLOGY}

\subsection{Research methodology}

The research methodology was divided into three stages. Stage 1 produced historical, material, and practical research through interviews, site visits, project analysis and research-based reading. This information was implemented on stage 2 to create a university course where to implement the work done on stage 1. Multiple projects were designed with student participation, that tested modularity and prefabrication. And the outcomes of this process were then used professionally, to create a prototype which was presented to an architectural competition in the subject. Stage 3 will get the project build (unfulfilled at the moment the article was written). A couple of possible clients were approached, and prefab companies in the locality of the sites have been consulted, but the construction process has been put on hold due to the shortage of labor and materials as a result of the pandemic. Following is the research methodology behind our work.

\subsubsection{Stage One}

Reviewed a selection of literature on the subject of prefabrication between the years of 2000 and 2021, pertinent to the goals of the process precented on this article.

Looked at historical precedent in multiple countries (Canada, Denmark, Japan, Spain, Norway, Sweden, United States, etc.) to understand the evolution of the prefabricated conceptual process and building systems. Documented past and existing prefabricated construction methodologies and applications.

There is presently no reliable assessment tool for assessing the efficiency of the prefabrication process. Based on our literature review and the opinions of prefab construction companies, the industrialization efficiency of prefabricated residential building could be checked based on the following criteria: The level of the standardization of the design, the amount of off-site manufacturing, the amount of on-site construction, the cost of the transportation of components, the efficiency of the Building Information Modeling (BIM) in simplifying the management of the project, and the sustainability of the process in terms of reduction of waste. But because every company has different production methods, comparing them becomes problematic. A lot more work needs to be done, to develop quantitative systems for this type of assessment [18].

Analyzed material options for the construction process to understand if there was a benefit in using local materials.

Discussed with prefab companies, their construction process, approach to regulations, costs, and sustainable approach. And observed the construction process in field trips to manufacturing facilities.

Discussed with participating workers the benefits to labor when compared to standard construction methodologies.

Discussed with architecture companies with prefabricated experience about their process.

Discussed with banks to better understand the loan mechanisms at the client's disposal to finance a prefabricated residential project.

\subsubsection{Stage Two}

Set up a studio course (400 level) in the Fall of 2020 at the College of architecture, Art, and Design (CAAD) to start to explore modularity. The work produced was exhibited in the Studio Gallery at City Center in Sharjah, UAE. 
Participated on the Modularity Home Design Challenge 2021 (set up by Bee Breeders Architectural Competition Organizer) to put our research and ideas into practice.

\subsubsection{Stage Three}

Implementation of a prefabricated design by finding a client interested in prefabrication.

Implementation of a design and construction process assessing the potential for implementing a creating a circular economy. This last point being a very complicated one, because presently the construction industry is set up as a linear economy rather than a circular one [19]. Making these changes hard when working at a project per project basis. COVID-19 has added to this issue by making sustainable materials scarce and hard to find. So, our approach has turned to one that focus on the use of local materials and working with construction companies that offer some level of circular economy management. The real implementation of this will be apparent once construction starts and sustainability within COVID-19 is explored within the construction process. Our research found that the implementation of a circular economy on the prefabrication process is still new but has potential of growth in the prefabrication industry. The reasons for its lack of implementation are mainly a lack of political awareness, resulting in no consequential government incentives.

\subsection{Design methodology}

- Drawing Preparation: In this stage, a design is produced focusing on how the modularity of the different elements will work together (Schematic Design \& Design Development). This stage uses all the research explained in the Research Methodology.

- Material estimation: In this stage, the design produced previously is developed to the detail level and used to estimate the material requirements of the project (Construction Documentation).

- Project duration: In this stage, the construction schedule is created based on the work needed to fulfill the proposed design accomplished in the last two stages. The construction schedule is done with the prefabrication company to adapt the design needs to their industrialized prefabrication process. Normally this process uses a critical path method.

- Cost Analysis: From the last three stages, the project cost is defined. These includes, design, labor, machinery cost and profit.

- Data Collection: By analyzing the schedule in action, we can assess elements that can be done more efficiently in the next build. This step is especially important when doing multiple dwellings. This process also helps defines the duration of the construction process.

- Project Duration: All the previous stages result in the information used to produce the construction schedule. Fig. 4 shows the implementation of this methodology compared to the traditional method for the project proposed on the following section.

\section{DESIGNING A PREFABRICATED DWELLING}

The project was designed to function in an urban lot as well as a sub-urban one. For this reason and with the idea to minimize on-site work, a foundation system was developed, named a spider-foundation. This system consisted of a structure lifted off the ground, designed to touch down only at specific points. Cement footings would be set only at the points of contact with the foundation system, no other site work would be needed except for 

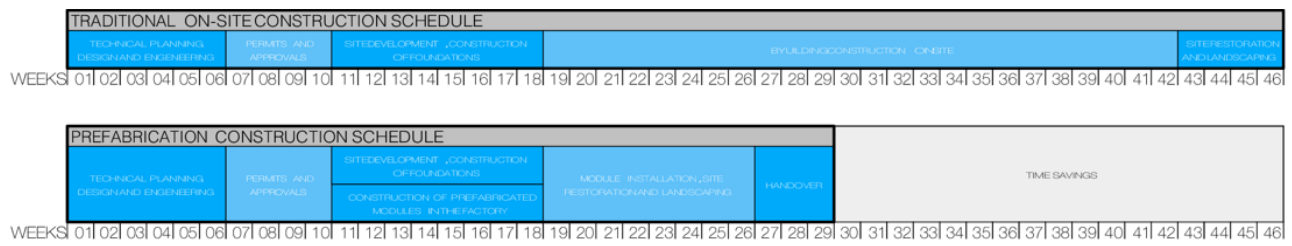

Figure 4: Typical construction process time comparison.

plumbing and electric work but only in cases were the house was not built to be selfsufficient. The result is a non-obstructive dwelling lifted from the ground. This system allows the house to be set in different topographies without having to flatten the land and it allows for flora and fauna to interact uninterrupted with the dwelling. Animals can even use the underside of the dwelling as shelter when needed. The foundation is then the first element to be set once the on-site construction process takes place. The competition brief called for a recommended maximum usable floor area of $90 \mathrm{~m}^{2}\left(968 \mathrm{ft}^{2}\right)$ and for the modules to be $3.6 \mathrm{~m}(11.8 \mathrm{ft})$ in height with a maximum module width of $4.2 \mathrm{~m}(13.7 \mathrm{ft})$ and a module length of $1.8 \mathrm{~m}(5.9 \mathrm{ft})$. Normally modular sizes are designed to fit the maximum size and load allowed in the area between the factory and the site. Because this size is dependent on the means of transport, this size is normally a lot larger than the competition requirements. To be able to work with the requested modularity in an efficient way, taking into consideration what we now understood of the prefabrication process, a house was designed based on an extruded volume that would allow us to break it into the number of modules needed to fulfil the program. The volume could not be any wider than $4.2 \mathrm{~m}$, this constrain forced the program to adapt into a proposal that would fit on a space generated by that width and the $90 \mathrm{~m}^{2}\left(968 \mathrm{ft}^{2}\right)$ of possible enclosed area. In this space we designed an open plan which would allow for a more fluid relationship between the kitchen, living room and dining room, but also from a practical perspective, it would provide a mainly empty space that could be cut where needed, into modules. On-site, once the foundation system has been set on the concrete footings, the modules can start to be installed by crane, one after the other and linked to the spider foundation and each other. You can see the process on Fig. 5. This process can be done in two days.

Following the module requirements, a volume composed of five enclosed and one open (to the weather) modules were designed. This dwelling used its longitudinal sides to enclose elements like the kitchen, toilet room, and shower within long built-in fixtures. These fixtures served to conceal the cut lines between modules giving the interior a sense of continuity. A smaller built-in volume separates the main space of the house from the master bedroom and serves as the children bedroom. By making all the modules the same size we ended up with a common shape that is repeated, making it a lot easier to build in the first phase of the factory process to be individualize only internally down the line. All the modules are basically the same element to which different aspects of the design get incorporated (Fig. 6). All exterior and interior work would happen on the factory, leaving minimal work done on-site post assembly. The construction process in factory of this design would take from 4 to 6 weeks. You can see the final product in Fig. 7. The house is designed to be self-sufficient, incorporating an atmospheric water generator to produce water, solar panels for energy, an interior hydroponic farm, a produce garden on the terrace, and a series of other technologies that make the house a net positive dwelling. The 

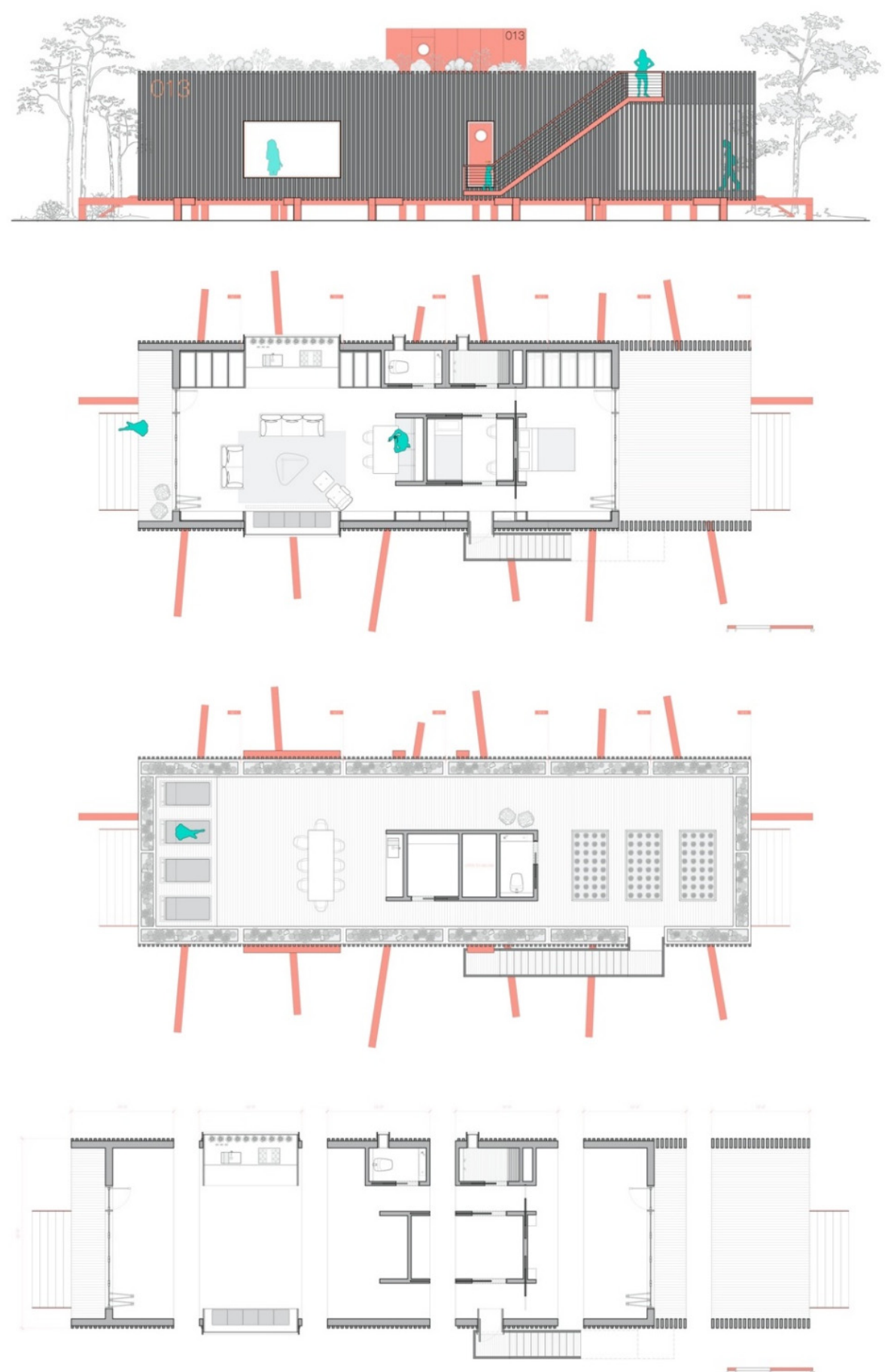

Figure 5: Side elevation, ground floor plan, terrace plan and separated prefabricated modules. 

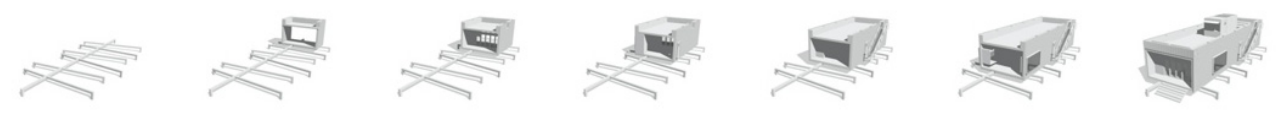

Figure 6: Modular assembly on site.

proposal, we estimate will cost $18 \%$ less than if it would have been built conventionally. By incorporating all the research into the design process and talking extensively to the people building factory manufactured houses, this project was designed for prefabrication and can be set up for Building Information Modeling (BIM). No one in the design team had any previous experience with Design for Manufacture and Assembly (DFMA) which forced us to adopt a strategy of overplanning. This forced the design team to consider, coordinate and finalize decisions much earlier than in the traditional design process. And even though the project has not been built yet, the design development and construction documentation process are finished since they would be needed immediately once a factory starts construction. A post construction analysis will be needed once the project is built which leaves for now, Stage 3 from the research methodology unfulfilled.

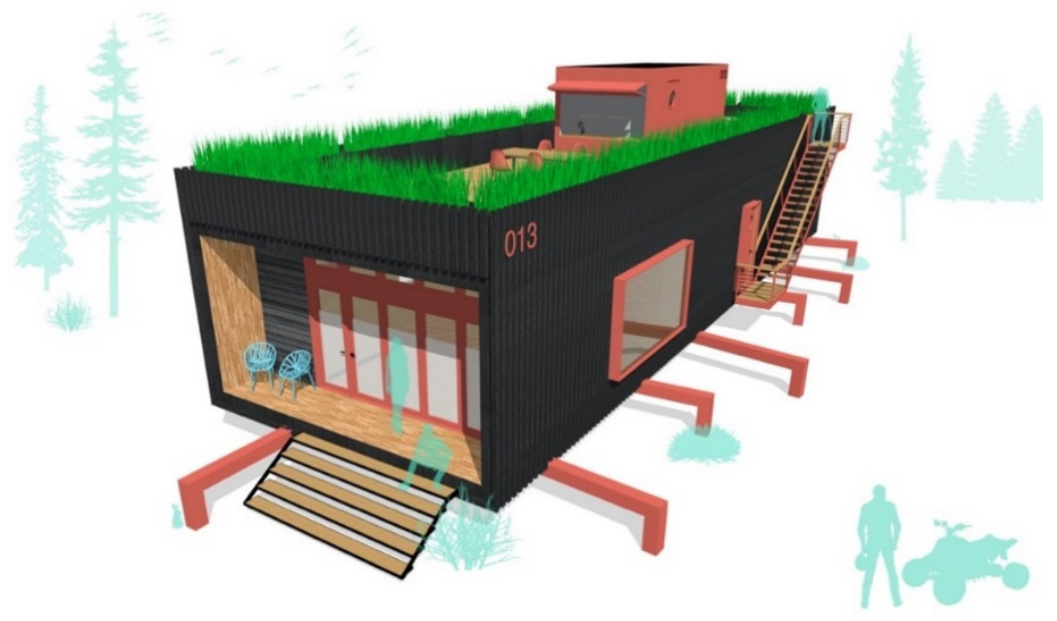

Figure 7: Modular single-family house with $1,012 \mathrm{ft}^{2}\left(94 \mathrm{~m}^{2}\right)$ of interior space $380 \mathrm{ft}^{2}$ $\left(35 \mathrm{~m}^{2}\right)$ of exterior covered space and $1,180 \mathrm{ft}^{2}\left(110 \mathrm{~m}^{2}\right)$ of terrace space.

\section{EXPECTED COST SAVING OBSERVATIONS}

Following we will discuss some observations that will help better understand the cost savings potential, for both client and owner, of the prefabrication process:

- Design Cost: Architects and designers will need to adapt to new ways of thinking about the design process keeping the prefabrication requirements in mind. Components will have to fit the maximum size and load allowed for transportation and as these elements are added to each other, the way they join together will also require a level of design adaptability. BIM will be an essential tool to achieve this. Once this process of adaptation ends, the results will manifest in a decrease in design costs. 
- Site Overhead: When compared to traditional construction, off-site manufacturing has already proven to reduce project schedules. The result is less management cost and site overhead because there is less work taking place on site.

- Material Cost: By buying materials in bulk, not using intermediaries, storing the materials in or near the factory and recycling or reusing materials from one project to the next material cost can be reduced.

- Labor Cost: Because $80 \%$ of traditional labor can be moved off-site and into the manufacturing facility, the more standardized and controlled construction environment will increase productivity. This move will also eliminate traditional on-site down time thanks to controlled scheduling, resulting in lower labor costs [9]. This process will also benefit the workers by giving them a safer workplace, always on the same location and not dependent on the weather.

- Logistics Cost: For the prefabrication system to work, the productivity gains need to outweigh the extra cost of transporting the finished units to the site.

- Financing Cost: For this system to function for the client, financial institutions need to adapt to the times. Lending rates for prefab manufacturing tend to be higher due to the novelty of the concept which is not yet fully understood by financial institutions. Because the prefabrication construction process functions differently than traditional construction, full payment is normally required upfront. Which also scares lenders.

- Factory cost: Setting up the manufacturing process for the owner of the company is a cost that needs to be taken into consideration against potential cost savings.

- Lifecycle cost: The increased in construction precision that results of the factorycontrolled environment has a significant impact on the quality, performance, and longevity of the building. The enclosed environment allows for closer scrutiny being placed on all the work being produced.

- Reuse cost: The reuse of buildings constructed with prefabricated techniques will be facilitated by easy dismantling.

\section{CONCLUSION}

Current traditional construction techniques do not reflect innovation trends and technology in the use of manufacturing for construction. We are building now in largely the same way we have for the last 70 years. Transitioning some types of construction to an offsite manufacturing model can produce the kind of dramatic productivity and environmental improvements that have long eluded the construction industry. Improving the productivity of such a large lagging sector of industry would result in economic growth. In an era of shrinking margins and growing costs in the construction industry, prefab housing is proving to be a necessity. In 2021, things can be done much more affordably, of better quality and more efficiently inside a factory. Where the use of new technologies provides a higher level of precision in the design and construction process. Using prefab technologies, like virtual design and construction (VDC) and building information modeling (BIM) are helping designers, engineers, builders, and fabricators communicate better, solving the construction's industry translation problem. The process has also allowed for a better system of controls and reviews, because most of the construction is done in a controlled environment where the production lines optimize the workflow. This level of productivity also reduces the risk of accidents since all the construction stages are not overlapped onto the same site as it is in traditional construction allowing for a cleaner environment. And one of the most significant prefab drivers is not just the cost savings in on-site building labor. It's the ability to build quickly in an industry lacking enough skilled workers. 
Prefabrication has also proven to be environmentally sustainable, due to upfront planning resulting in less material waste, less re-work, better scheduling, and less use of material in the finished product. Making it an industry perfectly set up for adopting circular economy systems as part of its process. While prefabrication alone is not going to solve the housing crisis, it is a first step toward a more equitable residential solution that together with other mechanisms can reshape the future of dwelling.

\section{ACKNOWLEDGEMENTS}

This research was supported by the American University of Sharjah and the College of Architecture, Art, and Design (CAAD). Special thanks to Bruce Klein for his constant barrage of emails pointing out new technologies. Maria Oliver for her historical research recommendations and help editing this paper.

\section{REFERENCES}

[1] Hari, K., U.S. Home Prices to Keep Racing Ahead with Risks to Upside, Reuters: London, 2021. https://www.reuters.com/business/us-home-prices-keep-racing-aheadwith-risks-upside-2021-05-24/.

[2] Freddie Mac, Housing Supply: A Growing Deficit, Freddie Mac: United States, 2021. http://www.freddiemac.com/research/insight/20210507_housing_supply.page.

[3] The US Census Bureau and the US Department of Housing and Urban Development, Monthly New Residential Sales-Apr. 2021, The US Census Bureau and the US Department of Housing and Urban Development: United States, 2021. https://www.census.gov/construction/nrs/pdf/newressales.pdf.

[4] Aladdin Company, Aladdin "Built in a Day", House Catalogue 1917, Dover Publications: United States, 1995.

[5] Sweet Rod, Why Sweden Beats the World Hands Down on Prefab Housing, Global Construction Review: United Kingdom, 2015.

https://www.globalconstructionreview.com/trends/why-sweden-beats-worldh8an0ds-4d2own0-6p4r2e0f8ab/.

[6] Arieff, A., Prefab, Proven, Dwell Magazine: United States, pp. 112-122, 2004.

[7] Mangialardo, A. \& Micelli, E., Innovation of Off-Site Constructions: Benefits for Developers and the Community in an Italian Case Study, Springer: New York, 2020.

[8] Minunno, R., O’Grady, T., Morrison, G.M. \& Gruner, R.L., Exploring Environmental Benefits of Reuse and Recycle Practices: A Circular Economy Case Study of a Modular Building, Elsevier Publishing: Amsterdam, 2020.

[9] Su, B., Heshmati, A., Geng, Y. \& Yu, X., A Review of the Circular Economy in China: Moving from Rhetoric to Implementation, MDPI Publishing: Basel, 2013.

[10] Turner, Cost Index, Turner: United States, 2021. http://www.turnerconstruction.com/ cost-index.

[11] Hendrix, M., Modular housing is affordable housing. National Review: New York, 2019.

[12] Bloom, E., Google is spending $\$ 30$ million on housing for silicon valley employees. CNBC: United States, 2017. https://www.cnbc.com/14 Jun. 2017/google-spending30-million-on-housing-for-silicon-valley-employees.html.

[13] Grothaus, M., Microsoft is spending half a billion dollars to make Seattle housing more affordable. Fast Company: United States, 2019. https://www.fastcompany.com/ 90293559/microsoft-is-spending-half-a-billion-dollars-to-make-seattle-housingmore-affordable. 
[14] Hilburg, J., New York city issues first call for affordable housing requiring modular construction. The Architects Newspaper: New York, 2018.

[15] Minunno, R., O’Grady, T., Morrison, G.M., Gruner, R.L. \& Colling, M., Strategies for applying the circular economy. MDPI Publishing: Basel, 2018.

[16] Cavalliere, C., Dell'Osso, G.R., Favia, F. \& Lovicario, M., BIM-Based Assessment Metrics for the Functional Flexibility of Building Designs, Elsevier Publishing: Amsterdam, 2019.

[17] United States Environmental Protection Agency, Construction and Demolition Debris: Material Specific Data, United States Environmental Protection Agency: United States, 2020. https://www.epa.gov/facts-and-figures-about-materials-wasteand-recycling/construction-and-demolition-debris-material.

[18] Xie, L., Chen, Y., Xia, B. \& Hua, C., Importance-performing analysis of prefabricated building sustainability: A case study of Guangzhou. Hindawi: London, 2020.

[19] Zairul, M., FlexZhouse: A New Business Model for Affordable Housing in Delft, BK Books: Delft, 2017. 